\title{
PENERAPAN PEMBANGKIT LISTRIK TENAGA PIKOHIDRO MENGGUNAKAN KOMPONEN BEKAS DENGAN PEMANFAATAN POTENSI ENERGI TERBARUKAN DI DESA GELANG KECAMATAN SUMBERBARU KABUPATEN JEMBER
}

\author{
Yusuf Ismail Nakhoda ${ }^{1 *}$, Irrine Budi Sulistiawati ${ }^{2}$, Aryuanto Soetedjo ${ }^{3}$ \\ 1,2,3 Jurusan Teknik Elektro, Institut Teknologi Nasional Malang \\ *Email Korespondensi: yusuf_nakhoda@lecturer.itn.ac.id
}

\begin{abstract}
ABSTRAK
Pembangkit listrik tenaga pikohidro merupakan salah satu alternative pembangkit listrik skala kecil yang dapat diterapkan di daerah pedesaan dimana tersedia aliran sungai yang mempunyai debit air yang kontinu dan tinggi jatuh air yang relative rendah untuk menggerakkan turbin yang dapat menghasilkan daya listrik. Untuk dapat menghasilkan daya listrik dengan potensi yang demikian, diperlukan pembangkit listrik tenaga skala pikohidro. Di Desa Gelang Kecamatan Sumberbaru Kabupaten Jember lokasi geografisnya merupakan sebuah dataran tinggi daerah perkebunan kopi dan teh, yang terdiri dari beberapa dusun dan kampung, diantara kampung dihuni oleh sekelompok warga Kampung Seng dan Kampung Genteng yang sampai saat ini belum menikmati listrik karena belum terjangkau jaringan listrik PLN. Dari hasil survei, kampung tersebut mempunyai potensi energy terbarukan berupa sungai yang mempunyai debit air kontinyu sepanjang tahun dan dapat dimanfaatkan untuk pembangkit listrik tenaga skala pikohidro. Pada program kemitraan masyarakat ditawarkan solusiya itu memanfaatkan potensi energi terbarukan yang ada pada kampung tersebut untuk menghasilkan daya listrik. Pada lokasi Kampung Seng dan lokasi Kampung Genteng dapat diterapkan pembangkit listrik tenaga skala pikohidro menggunakan komponen bekas, sedangkan keluaran daya listriknya dapat digunakan untuk mensuplai kebutuhan listrik pada Mitra (1) dan Mitra (2).
\end{abstract}

Kata kunci : energi terbarukan, pembangkit listrik tenaga pikohidro, komponen bekas.

\begin{abstract}
Picohydro is one of the alternative small-scale power plants that can be applied remotely for providing electricity service for a small urban area. That small-scale power plant is suitable for a hydropower resource which has a continuous water discharge and a low-fall of water level to generate adequate electrical power. The concept of a picohydro power plant is applied in Gelang Village, Sumberbaru Subdistrict, Jember Regency. The selected region is characterized by a plateau of coffee and tea plantations, which consists of several hamlets and villages. Moreover, the residents among villages inhabited by a group of Kampung Seng, have not yet enjoyed electricity due to unavailability of the electricity network from the utilities. From the field survey, those villages have a promising hydro resource with sufficient water level and continuous water discharge throughout the year. Through the community partnership program, a solution is proposed, utilising the renewable energy potential in the village to produce electricity. Situated at Kampung Seng and Kampung Genteng, a picohydro scale power plant is installed to provide the electrical power output can be used to supply electricity to the residents.
\end{abstract}

Keywords: renewable energy, picohydro power plant, used components.

\section{PENDAHULUAN}

Desa Gelang Kecamatan Sumberbaru Kabupaten Jember memiliki luas 4.293,34 m2 dengan ketinggian antara 0 - 1.330 mdpl. Iklim Desa Gelang adalah tropis dengan kisaran suhu antara $23^{\circ} \mathrm{C}-32^{\circ} \mathrm{C}$. Luas Wilayah Desa Gelang \pm 5.205,245 Ha, dengan batasan wilayah sebelah Utara berbatasan dengan Desa Andung Biru Kecamatan Tiris Kabupaten Probolinggo, sebelah Timur berbatasan dengan Desa Karangbayat Kecamatan 
Sumberbaru Kabupaten Jember dan sebelah Selatan berbatasan dengan Desa Karangbayat dan Desa Yosorati Kecamatan Sumberbaru Kabupaten Jember, sedangkan sebelah Barat berbatasan dengan Desa Jatiroto Kecamatan Sumberbaru Kabupaten Jember.

Dari hasil survei yang telah dilakukan bersama warga, pada kampung yang termasuk wilayah Desa Gelang yaitu Kampung Seng, kampung ini letak geografisnya merupakan dataran tinggi daerah perkebunan kopi dan teh serta mempunyai potensi energy terbarukan yaitu daerahnya dialiri sungai yang debitnya kontinyu sepanjang tahun sehingga apabila dimanfaatkan mempunyai potensi dapat menghasilkan energy listrik dengan skala pikohidro.

Sedangkan survei pada kampung lain yang berdekatan dengan Kampung Seng yaitu Kampung Genteng terdapat permasalahan khusus yang menyebabkan terbatasnya aktifitas warga kampung terutama pada malam hari, pada Kampung Genteng sampai saat ini belum menikmati listrik karena daerahnya belum terjangkau jaringan listrik dari PLN. Dari hasil analisis situasi dapat diidentifikasi pada saat survey lokasi dan potensi yang dimiliki terdapat permasalahan pada masing-masing Mitra dan solusi yang disepakati, yaitu:

\section{Permasalahan}

Permasalahan Mitra (1) di Kampung Seng dan Mitra (2) di Kampung Genteng adalah sebagai berikut:

a. Pada Kampung Seng dan Kampung Genteng belum terjangkau jaringa listrik PLN,

b. Di wilayah Kampung Seng dan Kampung Genteng sama-sama mempunyai potensi energy terbarukan berupa aliran sungai yang mempunyai debit air yang kontinyu sepanjang tahun, potensi sungainya apabila dimanfaatkan dapat menghasilkan daya listrik skala pikohidro.

c. Terbatasnya aktifitas kedua Mitra terutama pada malam hari karena tidak adanya lampu penerangan jalan.

d. Kurang maksimalnya kegiatan belajar anak-anak pada kedua Mitra karena minimnya sarana lampu penerangan.

\section{Solusi}

Hasil pembicaraan antara Tim Pengabdian kepada Masyarakat dengan Mitra (1) dan Mitra (2) didapatkan solusi yang disepakati untuk mengatasi permasalahan yang ada di Desa Gelang Kampung Seng dan Kampung Genteng yaitu di wilayah kedua Mitra di Kampung Seng dan Kampung Genteng yang mempunyai potensi energy terbarukan yang ada dimanfaatkan untuk menghasilkan daya listrik dengan penerapkan Pembangkit Listrik Tenaga Skala Pikohidro.

\section{METODE}

Untuk mencapai sasaran yang diinginkan dalam pengabdian kepada masyarakat ini, ada beberapa langkah pelaksanaan yang harus dilakukan seperti Gambar 1.

\section{HASIL DAN PEMBAHASAN}

\section{Perancangan Pembangkit Listrik Tenaga Pikohidro}

Untuk mewujudkan pembangkit listrik tenaga skala pikohidro, pertama kali yang harus dilakukan adalah survei lokasi sungai yang akan dipasang pembangkit listrik tenaga skala pikohidro sesuai dengan potensi aliran dan debit air yang mengalir pada sungai tersebut. Selanjutnya perancang konstruksi kincir/turbin air yang disesuaikan dengan potensi debit air yang ada di lokasi dan merancang posisi generator magnet permanen yang akan diputar turbin air melalui vanbelt, sehingga energi gerak putar dari turbin air dihubungkan pada poros generator sehingga menghasilkan energi listrik (Ahmad, 2014; Gatot \& Yusuf, 2007; Ihfazh, et al., 2013). 
Rancangan pembangkit listrik tenaga pikohidro didesain secara portabel agar dapat dipindah tempat dengan mudah. Gambar 2 dan 3 diperlihatkan rancangan pembangkit listrik tenaga pikohidro menggunakan generator magnet permanen (Ilyas \& Sahid, 2013; Puja \& Rozeff, 2017; Smith \& Ranjitkhar, 2000).

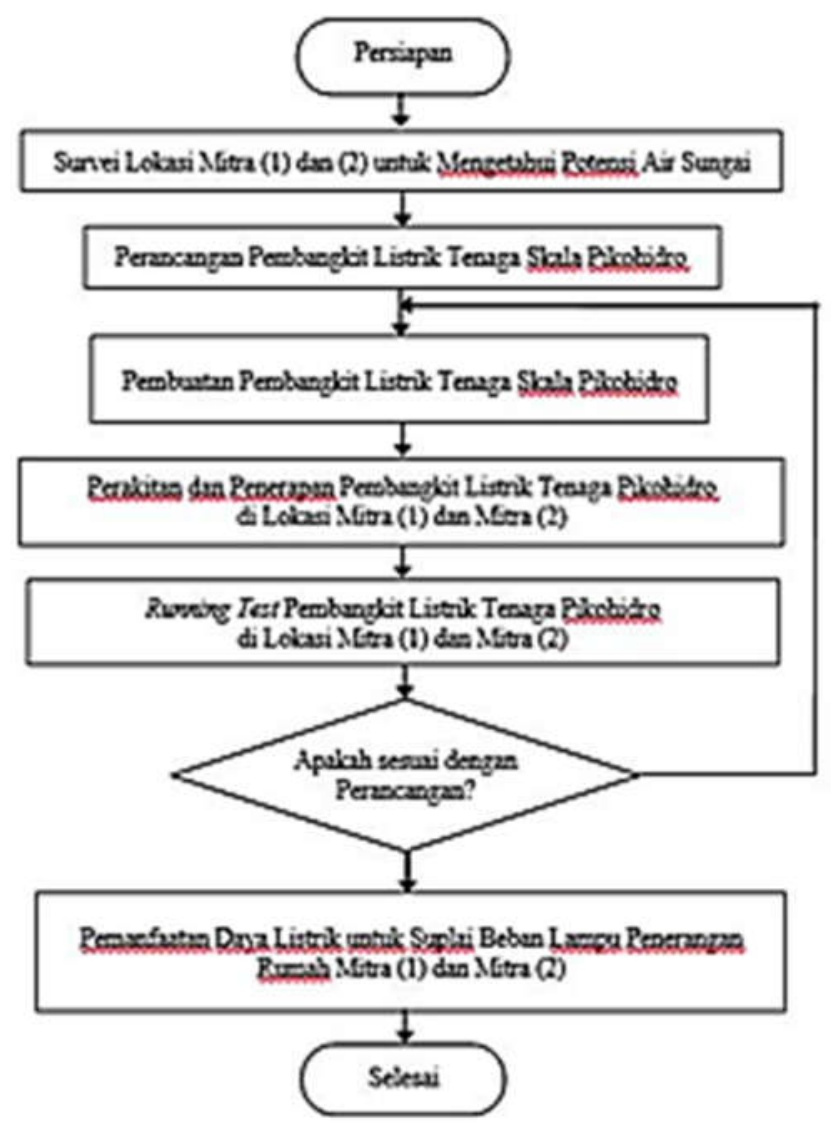

Gambar 1. Diagram alir metode pelaksanaan pengabdian kepada masyarakat

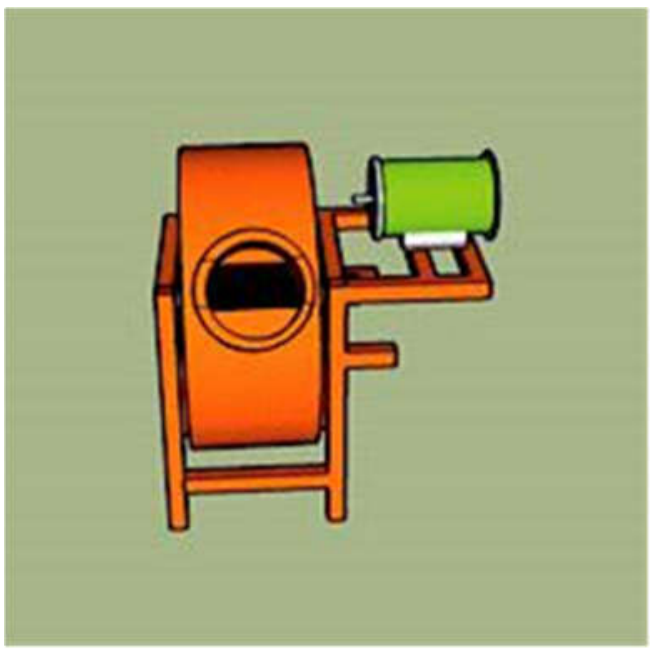

Gambar 2. Rancangan pembangkit listrik tenaga pikohidro menggunakan generator magnet permanen dilihat dari depan 


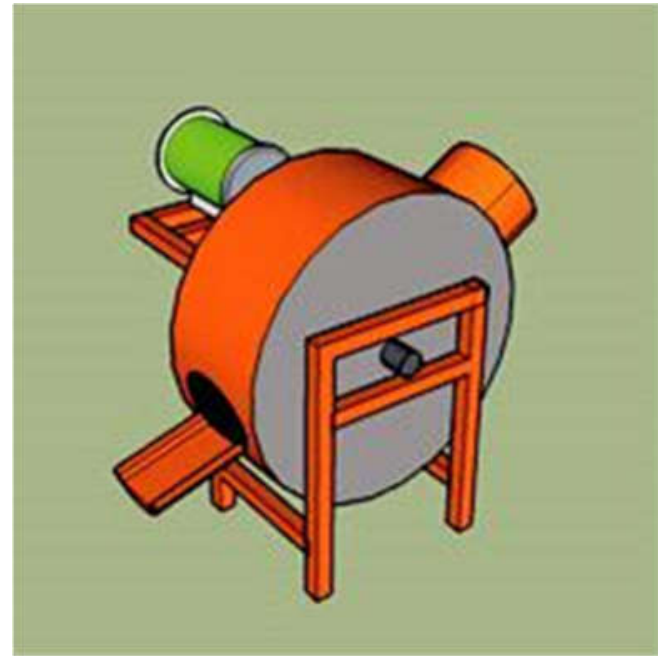

Gambar 3. Rancangan pembangkit listrik tenaga pikohidro menggunakan generator magnet permanen dilihat dari samping

\section{Pembuatan Pembangkit Listrik Tenaga Pikohidro}

Pada tahap pertama, pembuatan pembangkit listrik tenaga pikohidro yang harus dilakukan lebih dahulu yaitu membuat generator pikohidro dengan pengadaan rotor generator magnet permanen dari komponen bekas sepeda motor kemudian dimodifikasi dan dirakit menjadi rotor dengan jumlah 6 (enam) buah kutub magnet permanen kemudian dipasang poros. Selanjutnya membuat rumah stator generator dari pipa besi ukuran diameter 5 dim dipotong disesuaikan dengan panjang rotor generator. Rumah stator generator adalah tempat meletakkan lilitan kumparan kawat email yang terdiri dari 6 (enam) buah kumparan disesuaikan dengan besar diameter pipa besi. Agar generator tidak kena percikan air dari turbin air waktu berputar, maka didesain diberi tutup disisi depan dan disisi belakang generator kemudian dirapatkan dengan 3 (tiga) buah mur baut panjang (Shantika, et al., 2013; Zainuddin, 2008; Zulkarnaen, et al., 2002).

Gambar 4 dan 5 menunjukkan pembuatan lilitan kumparan stator generator magnet permanen dan 1 konstruksi dari rumah lilitan kumparan stator, rotor generator magnet permanen, mur-baut panjang pengikat dan tutup depan-belakang generator magnet permanen.

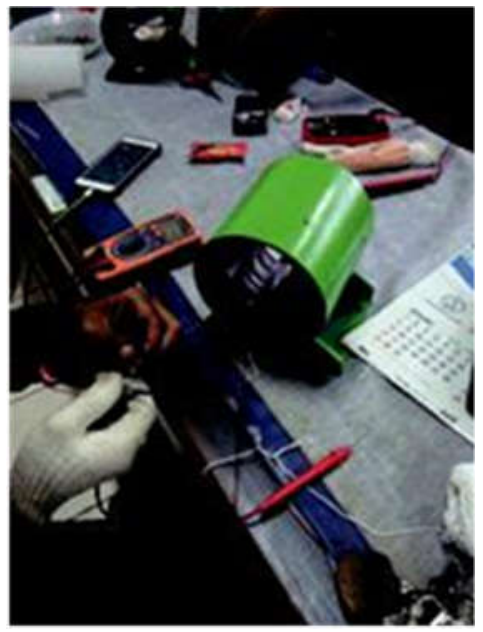

Gambar 4. Pembuatan lilitan kumparan stator generator magnet permanen 


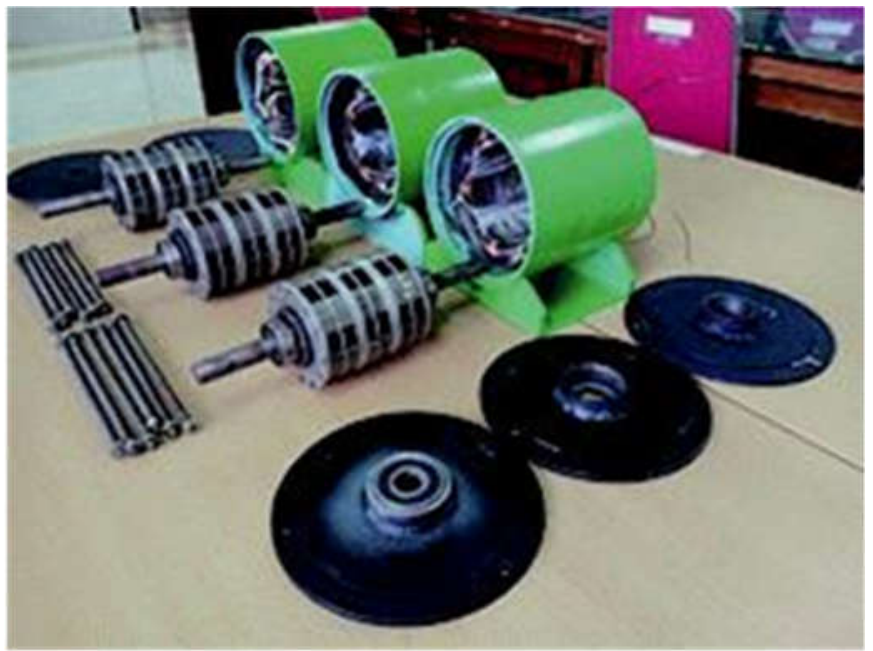

Gambar 5. Konstruksi dari rumah lilitan kumparan stator, rotor generator magnet permanen, mur-baut panjang pengikat dan tutup depan-belakang generator magnet permanen.

Tahap kedua, adalah pengujian laboratorium untuk mengetahui kinerja dari generator magnet permanen sebelum dirakit dengan turbin air pikohidro dan diterapkan di sungai yang berada pada lokasi mitra, tujuannya untuk mengetahui besar tegangan terendah sampai tertinggi apabila diputar menggunakan motor yang diputar dengan kecepatan (rpm) yang bervariasi tanpa dibebani, kemudian diujilagi dengan variasi kecepatan yang sama dengan dibebani lampu penerangan LED.

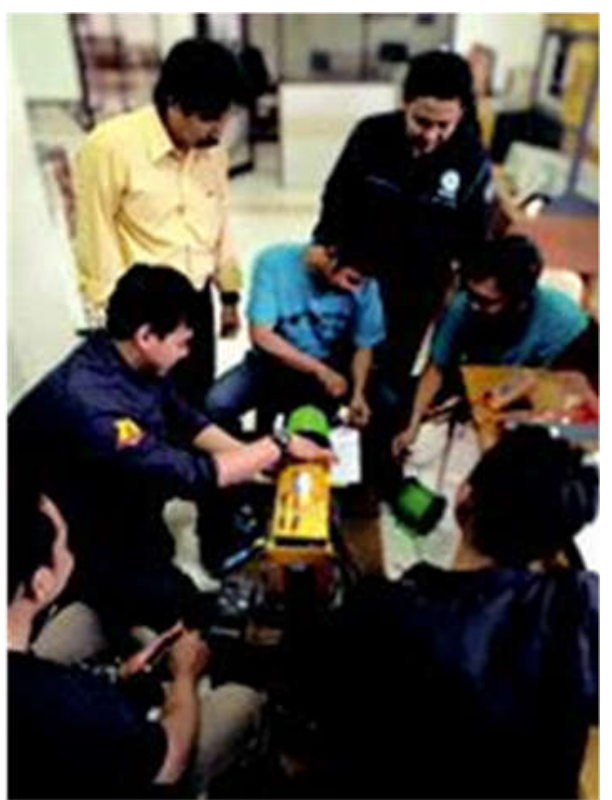

Gambar 6. Pengujian laboratorium tanpa beban dan berbeban untuk mengetahui kinerja dari generator magnet permanen.

Pada tahap ketiga, yaitu pembuatan kincir/turbin air pikohidro, kincir air adalah sebuah alat berbentuk lingkaran bagian dari sistem pembangkit listrik yang berfungsi untuk mengubah energi yang ada pada air menjadi energi gerak putardan memutar poros yang dihubungkan pada generator sehingga menghasilkan energi listrik. 
Turbin air pikohidro dibuat dari bahan plat besi yang terdiri dari 12 (dua belas) sudut dengan diameter $60 \mathrm{~cm}$, poros turbin diletakkan pada rangka pipa besi yang didesain secara portabel dan menyatu dengan generator magnet pernanen. Gambar 7 menunjukkan proses pembuatan 2 (dua) unit turbin air pikohidro dengan konstruksi dudukan turbin air yang didesain secara portabel agar lebih mudah untuk dipindah-pindah dan mudah untuk perawatan.

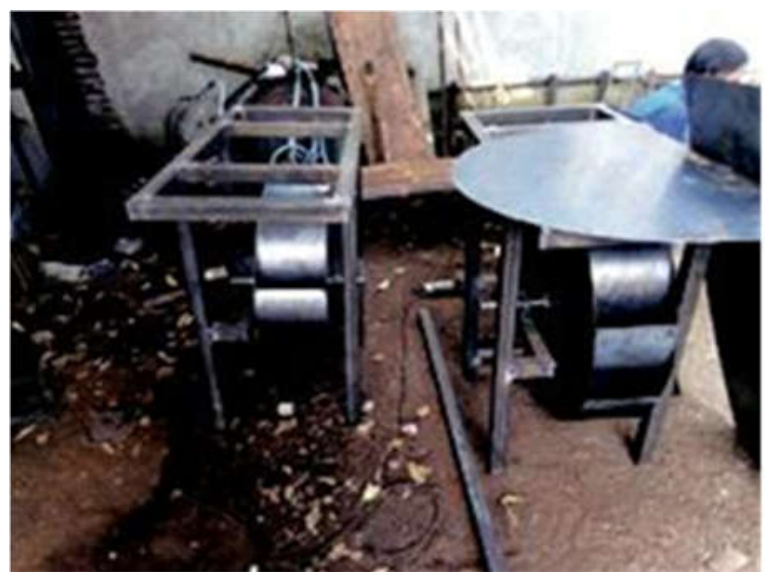

Gambar 7. Proses pembuatan turbin air skala pikohidro

Gambar 8 (a) dan (b) adalah hasil perakitan turbin air dengan konstruksi dudukan turbin air dan generator magnet permanen, pulley dan vanbelt yang menghubungkan turbin air dan generator magnet permanen dibuat sedemikian rupa agar pemasangan dan perawatannya lebih mudah dan praktis.

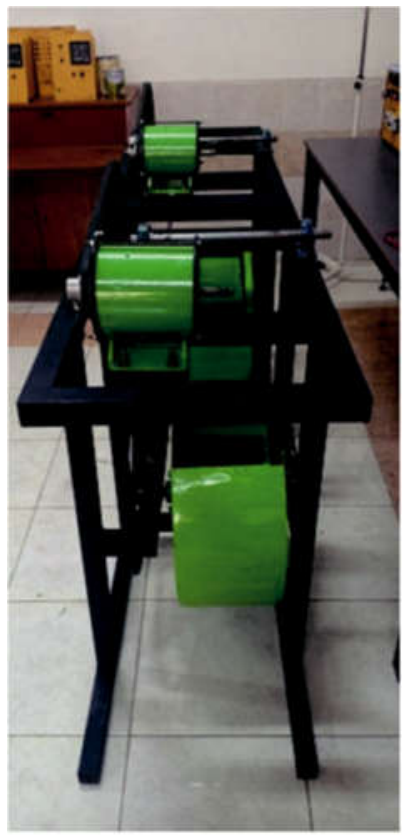

(a)

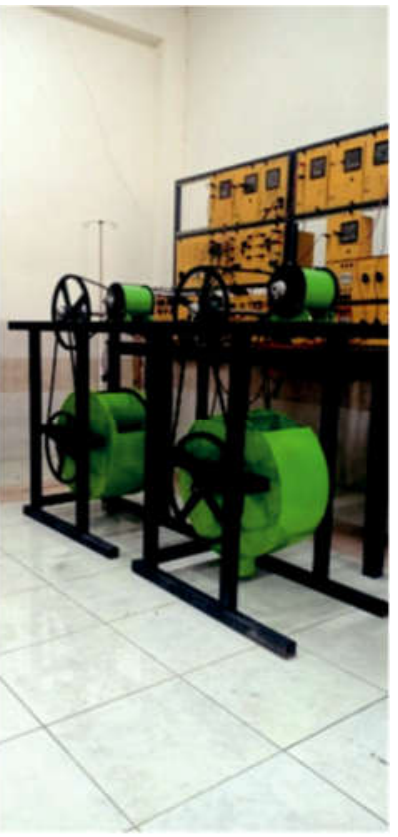

(b)

Gambar 8. Hasil perakitan turbin air, generator magnet permanen, pulley dan vanbelt yang menghubungkan turbin air dan generator (a) tampak depan dan (b) tampak samping. 
Tahap keempat,adalah tahap perakitan turbin air dan generator magnet permanen yang ditempatkan pada rangka pipa besi yang didesain portable kemudian dipasang pulley, sedangkan untuk menghubungkan turbin air dan generator dipasang vanbelt.

Tahap kelima, yaitu pemasangan pembangkit listrik tenaga pikohidro di Desa Gelang Kecamatan Sumberbaru Kabupaten Jember, di Kampung Seng dan Kampung Genteng. Prosesnya dimulai dari pengiriman 2 (dua) dua unit pembangkit listrik tenaga pikohidro ke lokasi Mitra (1) dan Mitra (2), kemudian pemasangan kedua unit pembangkit listrik tenaga pikohidro pada kedua Mitra.

Selanjutnya test running untuk mengetahui apakah putaran turbin sesuai dengan yang direncanakan. Langkah berikutnya yaitu memasang kabel dari keluaran generator ke rumah Mitra, di dalam rumah dipasang panel boks kontrol untuk merubah tegangan AC menjadi tegangan DC untuk mengecas accu, tegangan yang dikontrol dibatasi maksimum 15 Volt, kemudian keluaran dari accu melalui inverter tegangan DC dirubah menjadi tegangan AC 220 Volt untuk menyalakan sejumlah lampu penerangan LED.

Gambar 9 dan Gambar 10 menunjukkan proses pemasangan pembangkit listrik tenaga pikohidro pada lokasi Mitra (1) dan Mitra (2).

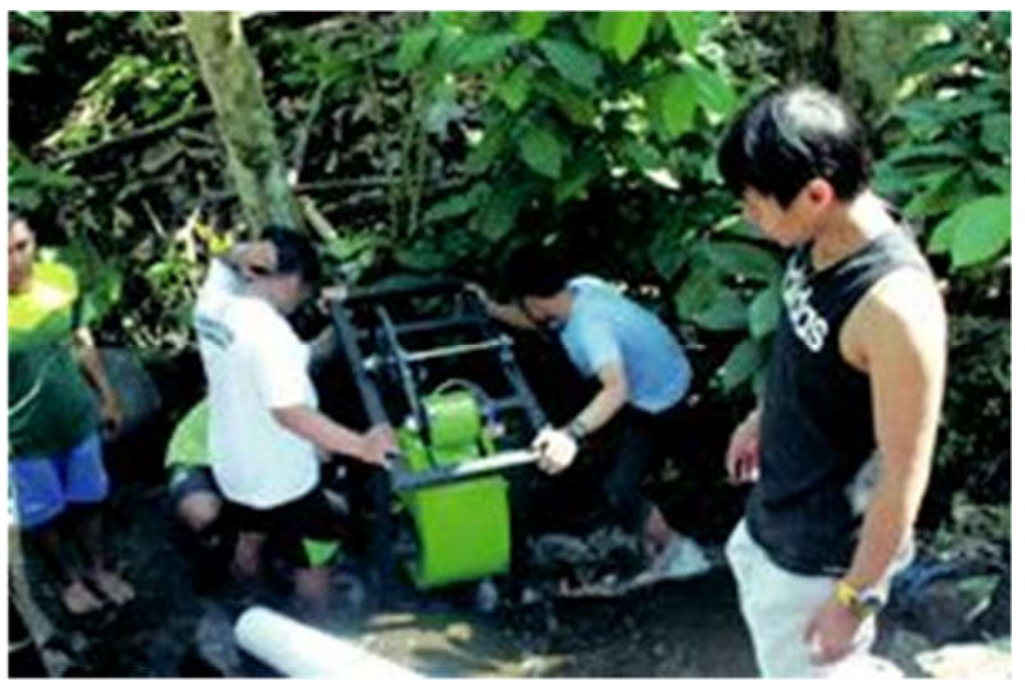

Gambar 9. Proses pemasangan pembangkit listrik tenaga pikohidro di lokasi Mitra (1)

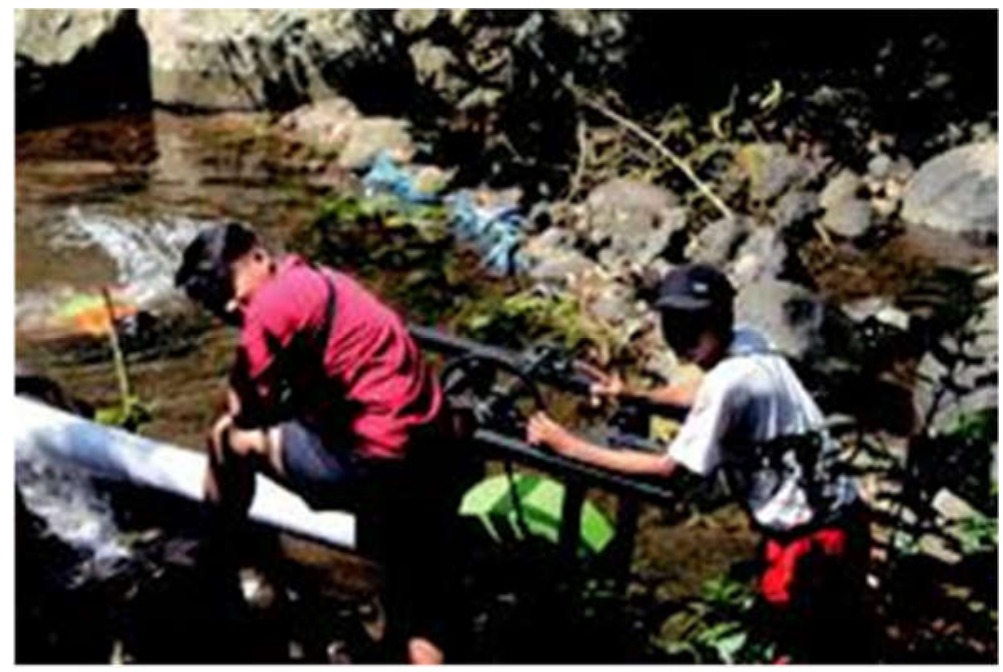

Gambar 10. Proses pemasangan pembangkit listrik tenaga pikohidro di lokasi Mitra (2) 
(Hal. 99-109)

Selanjutnya seperti yang ditunjukkan pada Gambar 11 dan Gambar 12 adalah running test terhadap kinerja pembangkit listrik tenaga pikohidro dan pengukuran tegangan keluaran generator magnet permanen.
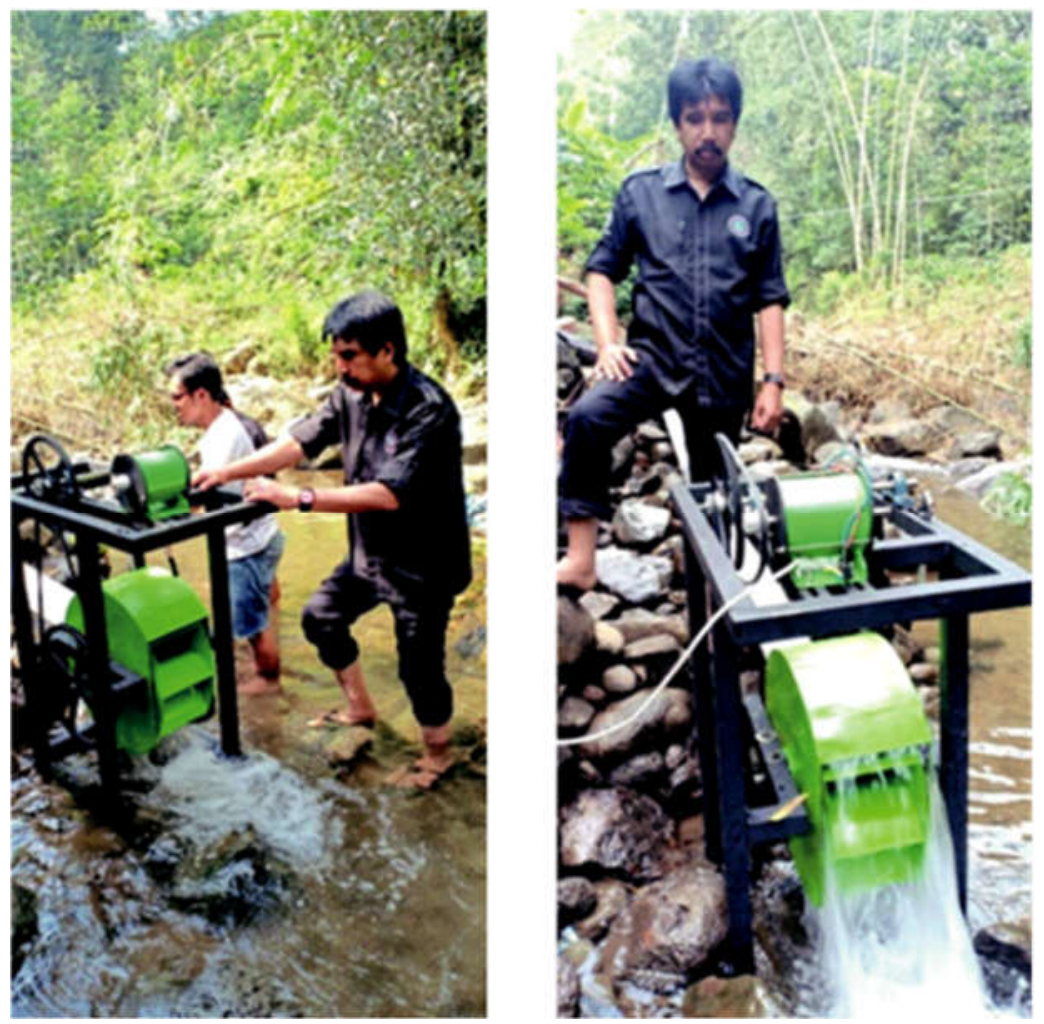

Gambar 11. Running test pembangkit listrik tenaga pikohidro

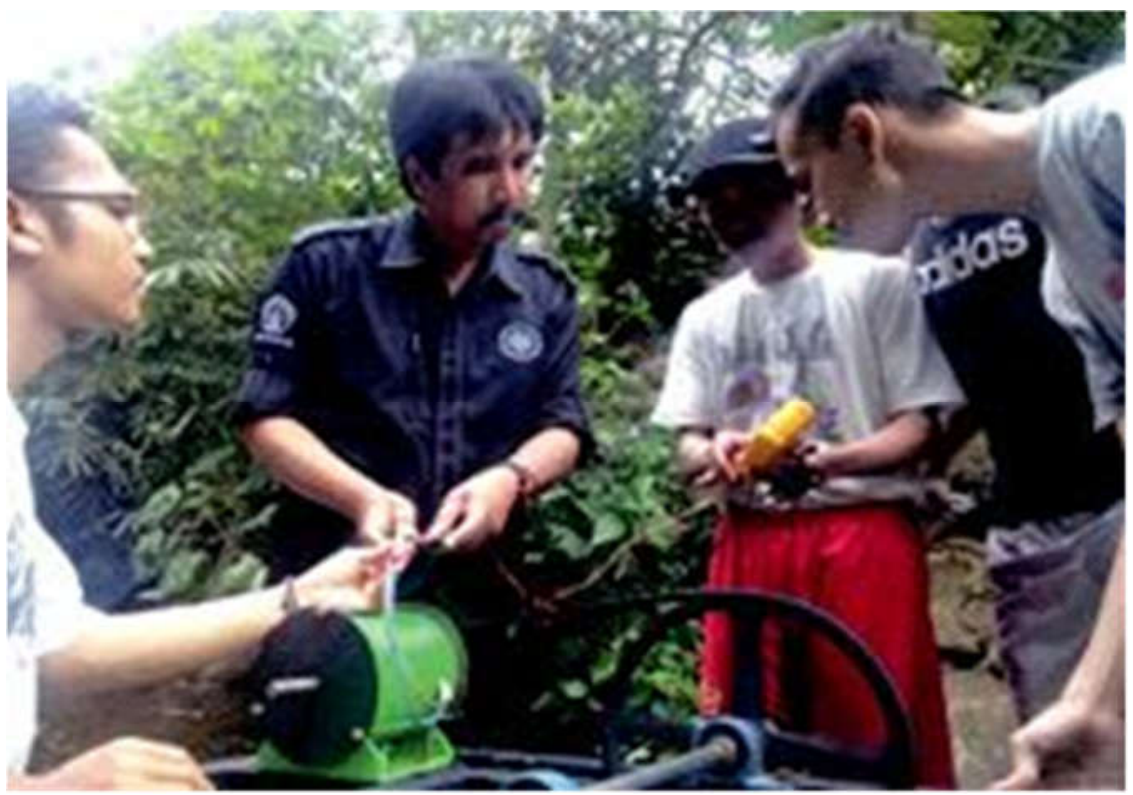

Gambar 12. Mengukur tegangan keluaran dari pembangkit listrik tenaga pikohidro. 
Tahap keenam, adalah pemasangansaluran kabel listrik dari pembangkit listrik tenaga pikohidro dan pemasanganpanel kontrol ke lokasi masing-masing rumah Mitra serta pemasangan lampu-lampu penerangan LED sesuai dengan kebutuhan pada rumah Mitra.

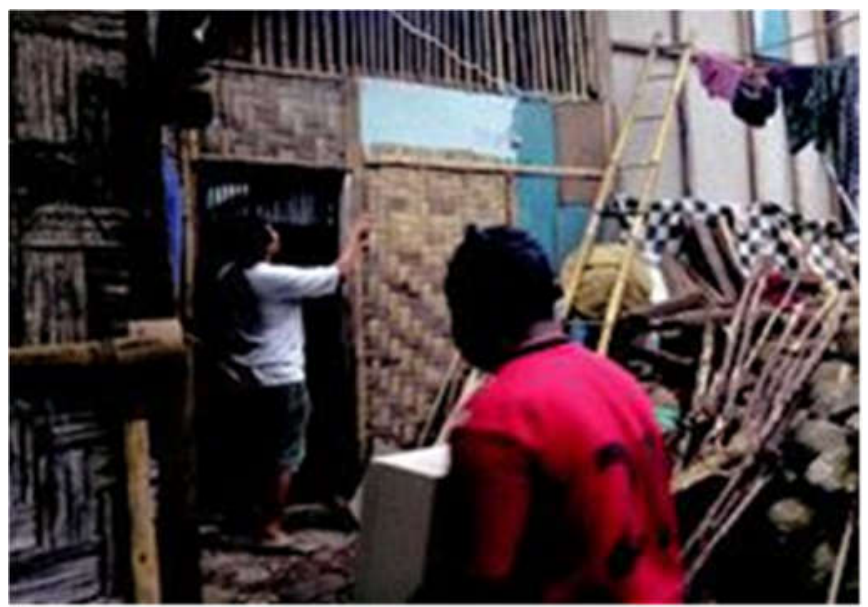

Gambar 12. Pemasangan saluran kabel listrik dari pembangkit listrik tenaga pikohidro ke lokasi rumah Mitra

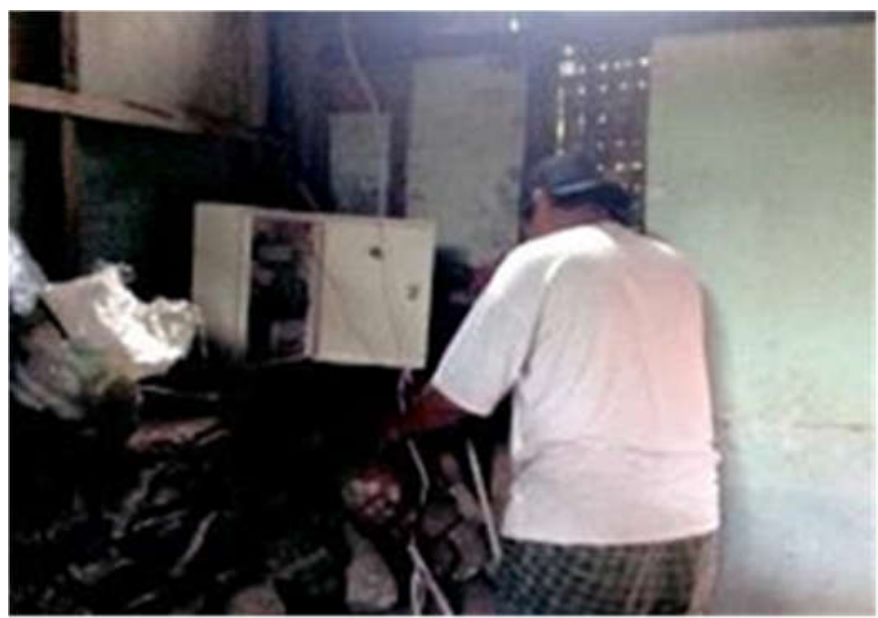

Gambar 13. Pemasangan panel kontrol di dalam rumah Mitra

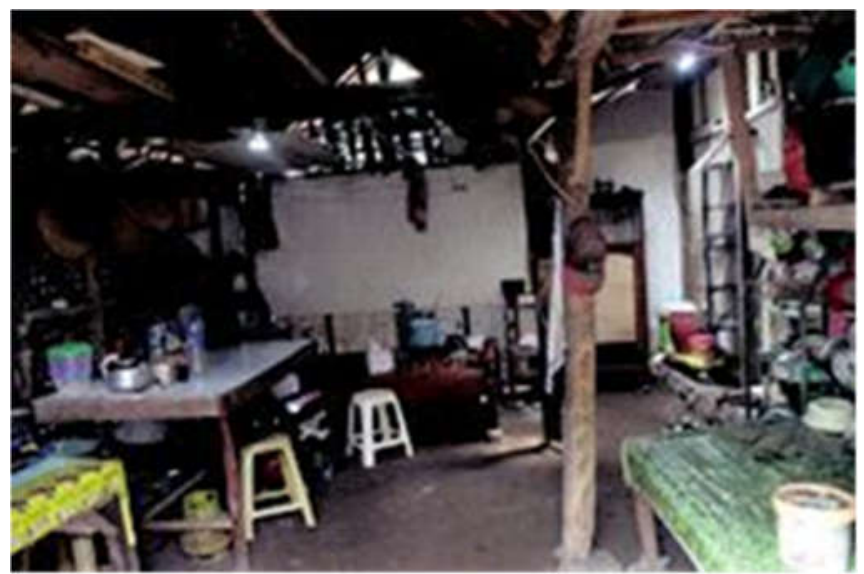

Gambar 14. Pemasangan lampu penerangan dalam rumah Mitra 
Tabel 1

Spesifikasi Generator Magnet Permanen

\begin{tabular}{|l|l|}
\hline \multicolumn{1}{|c|}{ Nama Komponen } & \multicolumn{1}{c|}{ Keterangan } \\
\hline Rotor & $5,21 \mathrm{~cm}$ \\
\hline Diameter Rotor & Neodymium \\
\hline Jenis Magnet & 24 batang \\
\hline Jumlah Magnet & 6 kutub \\
\hline JumlahKutub & $11,88 \mathrm{~cm}$ \\
\hline Stator & Tembaga \\
\hline Diameter Stator & Supreme \\
\hline Jenis Kawat Kumparan & 100 lilitan \\
\hline Tipe & $0,9 \mathrm{~mm}^{2}$ \\
\hline Jumlah Lilitan & $140-220$ Volt \\
\hline Ukuran Kawat & $1,3-1,4$ Ampere \\
\hline Generator & $180-300$ Watt \\
\hline Tegangan Keluaran & $50 \mathrm{~Hz}$ \\
\hline Arus Nominal & $600-1000 \mathrm{rpm}$ \\
\hline Daya & 1 fasa \\
\hline Erekuensi & Crossflow \\
\hline Putaran & 10 buah \\
\hline Easa & $1: 5$ \\
\hline Turbin Air & \\
\hline Jenis & \\
\hline Jumlah Sudu & \\
\hline Perbandingan Pulley &
\end{tabular}

\section{DAMPAK DAN MANFAAT}

Pembuatan pembangkit listrik pikohidro dapat menghasilkan listrik yang dapat digunakan untuk penerangan di rumah-rumah untuk daerah terpencil di daerah Desa Gelang Kecamatan Sumberbaru, Kabupaten Jember. Di Kampung Seng dan Kampung Genteng terdapat 37 kepala keluarga yang semuanya membutuhkan aliran daya listrik untuk kebutuhan terutama penerangan lampu, karena rata-rata rumahnya berdekatan dengan sungai yang aliran airnya sepanjang tahun, sebaiknya setiap rumah memiliki pembangkit listrik tenaga skala pikohidro. Karena setiap rumah membutuhkan penerangan lampu, maka dengan perkembangan teknologi lampu LED lebih cocok diterapkan di kampung ini karena konsumsi daya listriknya rendah dan dapat dipasang sejumlah lampu yang disesuaikan dengan kapasitas daya keluaran dari pembangkit listrik tenaga skala pikohidro yang relatif kecil.

\section{KESIMPULAN}

Di Desa Gelang Kecamatan Sumberbaru, Kabupaten Jember lokasi geografisnya merupakan sebuah dataran tinggi daerah perkebunan kopi dan teh, yang terdiri dari beberapa dusun dan kampung. Dari hasil survei, kampung tersebut mempunyai potensi energy terbarukan berupa sungai yang mempunyai debit air kontinyu sepanjang tahun dan dapat dimanfaatkan untuk pembangkit listrik tenaga skala pikohidro. Pada program kemitraan masyarakat ditawarkan solusi yaitu memanfaatkan potensi energi terbarukan yang ada pada kampung tersebut untuk menghasilkan daya listrik. Pada lokasi Kampung Seng dan lokasi Kampung Genteng dapat diterapkan pembangkit listrik tenaga skala pikohidro menggunakan komponen bekas, sedangkan keluaran daya listriknya pada Mitra (1) sebesar180-300 Watt dan Mitra (2) sebesar 180-300 Watt, sehingga dapat mensuplai kebutuhan listrik yang digunakan untuk beban lampu penerangan rumah sehari-hari. 


\section{REFERENSI}

Ahmad, R. Y. (2014) 'Optimalisasi Pengoperasian Pembangkit Listrik Tenaga Air Berskala Pico Hydro', Universitas Pendidikan Indonesia | repository.upi.edu | perpustakaan.upi.edu

Gatot, S. B. dan Yusuf D. H. (2007) 'Optimasi Turbin Crossflow Terhadap Variasi Sudut Sudu Pengarah untuk Pembangkit Listrik Tenaga Mirohidro', Jurnal Eksergi, Vol. 3 No. 1 Hal. 9-16, ISSN 0216-8685.

Ihfazh, N. E. N, Waluyo, dan Syahrial (2013) 'Penerapan dan Analisis Pembangkit Listrik Tenaga Pikohidro dengan Turbin Propeller Open Flume TC 60 dan Generator Sinkron Satu Fasa 100 VA di UPI Bandung', Jurnal Reka Elkomika, Vol.1 No.4, ISSN 2337-439X.

Ilyas R. dan Sahid (2013) 'Rancang Bangun Model Turbin Crossflow sebagai Penggerak Mula Generator Listrik Memanfaatkan Potensi Pikohidro', Jurnal Eksergi, Vol. 9 No. 2 Hal. 56-60, ISSN 0216-8685.

Puja, S. dan Rozeff, P. (2017) 'Rancang Bangun Mini Generatoe Fluks Aksial 1 Fasa Putaran Rendah Menggunakan Neodymium Magnet (NdFeB) Berbasis Multi Cakram', FT. UMRAH.

Smith, N. dan Ranjitkhar, G. (2000) 'Nepal Case Study-Part One: Installation and Performance of the Pico Power Pack'. Pico Hydro Newsletter.

Shantika, T., Aelxin, P. dan Ryan, C. O. (2013) 'Perekayasaan Pembangkit Listrik Tenaga Air Untuk Penyediaan Listrik Skala Kecil', Jurnal Riset Industri, vol.7 Hal 145,146 dan 147.

Zainuddin H, (2008) 'Investigation on the Performance of Pico-hydro Generation System Using Consuming Water Distributed to Houses'.

Zulkarnaen, Hari, S. dan Akbar, B. (2002) 'Sistem Pikohidro untuk Daerah Terpencil', Publikasi P3TEK Informasi Energi dan Ketenagalistrikan, Vol. 1, No. 1, April. 